\title{
EL ESQUEMA DISTRIBUTIVO DE RECURSOS DE RONALD DWORKIN: TOMANDO LA IGUALDAD DE CAPACIDADES EN SERIO
}

\author{
Ronald Dworkin's Scheme for the Distribution of Resources: Taking Seriously the Equality of Capacities
}

Miguel Garcia-Godinez

\section{Resumen}

De acuerdo con el esquema distributivo de Dworkin, la distribución y redistribución equitativa de recursos está determinada por la elección libre e informada de las personas. Ellas deciden qué recursos necesitan para realizar sus proyectos de vida. Si este esquema satisface, además, el principio regulativo de igual consideración, la noción de libertad e igualdad dejan de ser antagónicas. De esta forma, defiende Dworkin, se puede fundamentar una comunidad liberal igualitaria. Este trabajo explora la noción de persona y atribución de responsabilidad para justificar que, entendiendo las condiciones de elección libre e informada como capacidades básicas individuales, la teoría de la justicia de Dworkin no es solo una teoría de igualdad de recursos, sino también de igualdad de capacidades.

\section{Palabras clave}

Igualdad de recursos, igualdad de capacidades, justicia, libertad, responsabilidad.

\section{Abstract}

According to Dworkin's distributive scheme, the free and informed choice of persons determines the fair distribution and redistribution of resources. They decide what resources they need to realise their life projects. Moreover, if this scheme satisfies the regulative principle of equal concern, then the notion of liberty and equality are no longer antagonistic. This way, holds Dworkin, it is possible to ground a liberal egalitarian community. This paper elaborates on both the notion of person and responsibility attribution to justify that, by understanding the conditions of free and informed choice as individual basic capacities, Dworkin's theory of justice is not only a theory of equality of resources, but also of equality of capacities.

\section{Key words}

Equality of resources, equality of capacities, justice, liberty, responsibility

\footnotetext{
${ }^{1}$ University of Glasgow (Escocia). Correo electrónico: j.garcia-godinez.1@research.gla.ac.uk
} 


\section{Introducción}

Una de las mayores aportaciones filosóficas de Ronald Dworkin al debate contemporáneo sobre la justicia, fue su esquema distributivo de recursos. La importancia de este esquema puede señalarse mencionando tan solo dos de sus características más relevantes. Primero, se trata de un esquema que pretende asegurar (inicial y progresivamente) una distribución justa de los recursos disponibles en un contexto determinado, así como fundamentar, a partir de ella, una comunidad liberal igualitaria. Segundo, en la medida en que este esquema cumple con los procedimientos equitativos para la distribución y redistribución de los recursos, y preserva coherencia con el principio regulativo de igual consideración, consigue mantener el valor objetivo del proyecto de la igualdad de recursos (IR): asegurar la igualdad entre los miembros de una comunidad sin sacrificar en absoluto sus libertades.

En términos generales, para Dworkin el equilibrio entre igualdad y libertad es precisamente lo que caracteriza a una comunidad liberal igualitaria. Esta tesis va a constituir la base de su esquema distributivo y, en consecuencia, el eje central de su IR: en una comunidad liberal igualitaria, la igualdad y la libertad no son vistas como valores políticos contrapuestos, sino que, bajo una interpretación adecuada de la justicia, ambos valores son considerados condiciones mutuas de realización. Esta interpretación de la justicia, que Dworkin llama "distributiva», es un paso necesario para llegar a la conclusión de que la moral política de la democracia liberal es la igualdad. Una igualdad que, para Dworkin, tiene que ver tanto con corregir las desigualdades que se deben a la fortuna y a la lotería natural, como con asegurar un trato igualitario a los distintos proyectos de vida de las personas. ${ }^{2}$

Qué entiende Dworkin por «persona», no es del todo claro. $\mathrm{Su}$ uso, sin embargo, parece responder a la noción que usualmente se asocia a la concepción liberal de individuo, esto es, un agente racional autónomo. Esta noción es imprescindible para el proyecto de Dworkin, porque es gracias a ella que se podrán definir las afectaciones que se pueden o no compensar según el esquema distributivo de la IR. Que haya afectaciones personales y afectaciones impersonales es lo que lleva a Dworkin a concluir que hay casos en los que la justicia obliga a redistribuir los recursos, y casos en los que hacerlo es injusto. Reconocer esa distinción no es más que fijar el límite entre los casos de responsabilidad y los casos de no-responsabilidad, cuya atribución se decidirá según las condiciones de autonomía y racionalidad que las personas satisfagan.

Si esas condiciones de autonomía no son satisfechas, entonces el esquema distributivo de Dworkin no debería condenar una elección de vida poniéndola fuera del conjunto de las afectaciones impersonales; es decir, si las condiciones que permiten a una persona tomar una decisión libremente y sin restricciones de información relevante no son cumplidas, entonces la elección que se tome debería tenerse por una falla en el funcionamiento del individuo y hacerse, por eso mismo, susceptible de compensación.

Si esto es así, se puede entonces afirmar la tesis de que la IR de Dworkin incluye no solo un esquema distributivo de recursos sino también una exigencia de satisfacción de condiciones de autonomía y racionalidad; es decir, una exigencia de igualdad de capacidades. A esta exigencia, apelando a su idea del mercado hipotético de seguros, le sigue un modelo de asimilación institucional (uno de carácter impositivo o tributario).

Para justificar esta idea, primero, (1) expondré brevemente el esquema distributivo de Dworkin, y luego, (2) explicaré la noción de persona que parece justificar su propuesta. Además, trataré de fijar, a partir de ella, las condiciones de responsabilidad respecto de la elección del proyecto de vida, de los recursos que necesitan para llevarlo a cabo y de la estrategia de aseguramiento contra las afectaciones impersonales. Aquí se mencionará, además, que estas condiciones son las que permiten a las personas tomar ciertas decisiones y no otras, y son las que justifican la obligación de que sean ellas quienes asuman los costos que esas decisiones producen. Por último, (3) defenderé que hay una noción de igualdad de capacidades que parece derivarse de las condiciones de libertad y responsabilidad que caracterizan la IR de Dworkin.

\section{El esquema distributivo de la IR}

En el primer capítulo de su Virtud Soberana, ${ }^{3}$ Dworkin reconstruye dos versiones de la igualdad de bienestar, o de lo que suele denominarse «bienestarismo»: la igualdad de éxito y la igualdad del estado mental. Con base en esa reconstrucción, Dworkin argumenta que el bienestarismo

\footnotetext{
2 Dworkin (2000: 1-7).

${ }^{3}$ Dworkin (2000: 11-64).
} 
(en cualquiera de sus dos versiones) fracasa como la mejor interpretación posible de la justicia distributiva, porque no respeta la exigencia de tratar a las personas como iguales. De ahí su propuesta de evaluar, entonces, una teoría de la igualdad de recursos. ${ }^{4}$ Una teoría cuyos atributos principales serían, por un lado, el respeto irrestricto que guarda a los dos principios de la teoría liberal comprensiva: el principio de igual importancia y el principio de responsabilidad especial; y, por otro lado, la incorporación de su concepción de igualdad, que incluye la exigencia de tratar a todas las personas como iguales, admitiendo la compensación para aquellos casos de desigualdad que se encuentran fuera del margen de responsabilidad de las personas.

De manera breve, se podría decir que el primer principio de su teoría liberal comprensiva, es decir, el principio de igual importancia, afirma que toda vida humana tiene un valor objetivo: una vez que la vida comienza, importa cómo va; es buena cuando tiene éxito y sus potencialidades son alcanzadas, y es mala cuando fracasa y sus potencialidades son desperdiciadas. El segundo principio, esto es, el de responsabilidad especial, sostiene en cambio que cada persona tiene la responsabilidad de realizar exitosamente su propia vida; una responsabilidad que incluye ejercer su propio y autónomo juicio acerca de qué tipo de vida sería exitoso llevar. ${ }^{5}$

Fundamental para entender la aplicación de estos principios liberales, y en general la propuesta de la IR, es poner en claro la noción de persona que se está utilizando. De acuerdo con Dworkin, ${ }^{6}$ la persona es quien decide, en atención a sus propias consideraciones, qué vida llevar en relación con la cantidad de recursos disponibles. Esa cantidad de recursos es lo que debe tomar en cuenta la persona cuando decide qué sacrificar para favorecer ciertos planes o proyectos de vida. En ese cálculo, la persona considera no solo los recursos sociales sino también los naturales (salud, talento y capacidades) para después compararlos con los de las demás personas y evaluar así sus oportunidades de éxito.
Como el objetivo de la IR es la distribución igualitaria de recursos, que no es otra cosa que dar a cada persona lo necesario para que realice sus propios proyectos de vida, Dworkin sostiene que es la mejor alternativa para conseguir un trato igualitario en el sentido más básico: la distribución se acomoda a las concepciones del bien y a los planes de vida que cada persona elige. La IR es, en consecuencia, una teoría de la justicia sensible a las ambiciones personales. ${ }^{\text {? }}$

Para no perder esta sensibilidad, el método de distribución que debe incorporar la IR es solo aquel que pueda asegurar a cada persona «el peso de sus propias decisiones». Los recursos, que son el objeto que se va a distribuir, son exclusivamente medios que se valoran según la concepción de vida de las personas. De modo que la adecuación que el esquema distributivo tiene que conseguir entre personas y recursos depende de que estos sean elegidos libremente y según el proyecto de vida seleccionado. Cualquier criterio que se emplee para decidir si una distribución es justa o no, tiene que ser aplicado en términos exclusivamente individuales, ya que la igualdad que está en juego es sensible a las decisiones de las personas y no a las de los grupos o clases sociales.

No es fácil hacer una descripción breve del esquema distributivo de Dworkin, ni mucho menos hacerlo sin anotar todos los detalles relevantes; sin embargo, es inevitable intentar aquí una reconstrucción que ponga en su lugar los puntos que interesa discutir en este trabajo. Para hacerlo, dividiré en tres niveles distintos el esquema distributivo de la IR. En el nivel hipotético, se considera la situación hipotética de los náufragos, y una primera versión de distribución de recursos. En el nivel extendido, se consideran algunas situaciones aleatorias que afectan los resultados del primer nivel. Finalmente, en el nivel institucional, se propone incorporar procedimientos y resultados del primero y segundo nivel a las prácticas institucionales de las sociedades económicamente más complejas.

\footnotetext{
${ }^{4}$ Según Arneson (2004:93), una teoría de la igualdad de recursos «sostiene que el objetivo [...] es conseguir para cada individuo una parte equitativa de los recursos y oportunidades, más que intentar producir un patrón de resultados que tenga lugar a partir de los usos de los recursos que las personas hacen. Este punto de vista consiste en hacer a las personas responsables por sus propios fines, en el sentido de que los individuos quienes han recibido partes equitativas de recursos no tienen derecho a una compensación adicional sobre la base de que sus elecciones de estilo de vida resultaron ser tan costosas que no pueden alcanzar mayor satisfacción de sus fines sin la ayuda de la sociedad. Lo que cuenta como una parte equitativa de recursos está determinado independientemente de los objetivos y ambiciones que un individuo afirma. Por el contrario, los principios bienestaristas de la justicia distributiva sostienen en principio que las partes de recursos individuales deberían ajustarse para permitir que cada quien alcance una cantidad justa (a fair extent) de bien-estar o bienestar».

${ }^{5}$ Dworkin (2006: 9s).

${ }^{6}$ Dworkin (2000: 69).

7 Dworkin (2000: 108) y Dworkin (2002: 107).
} 


\section{El nivel hipotético}

Para saber qué modelo de propiedad privada constituiría una distribución equitativa de los recursos privados, ${ }^{8}$ Dworkin piensa una situación apenas posible en la que un grupo de náufragos llega a una isla de la cual no hay manera de ser rescatados, y en la cual abundan ciertos recursos y no hay población humana que reclame derechos sobre ellos. ${ }^{9}$ En esa situación, dice Dworkin, los náufragos tienen que emplear algún método para distribuir equitativamente los recursos. El criterio que pueden utilizar para decidir sobre la equidad de su distribución es el test de la envidia. Según este test, no hay distribución equitativa si una vez que se distribuyeron todos los recursos, queda algún náufrago que todavía prefiere el paquete de recursos de algún otro. ${ }^{10}$

Si los náufragos eligieran a uno de ellos para hacer la distribución siguiendo este test, el elegido no podría simplemente dividir equitativamente los recursos entre el número de náufragos que constituyen el conjunto de los sobrevivientes. Primero, porque hay algunos recursos que no son divisibles, $y$, segundo, porque hay otros que, aunque sean divisibles no se pueden considerar a todas sus partes igual de valiosas o aprovechables (lo cual terminaría por violentar el test de la envidia, dado que conduciría a la situación en la que algún náufrago tuviera un paquete tal que preferiría tener el paquete de recursos de alguien más).

El elegido tampoco podría lograr la distribución equitativa mediante la técnica de ensayo y error. Aunque lograra crear $\mathrm{n}$ número de paquetes de recursos, con algunas diferencias entre ellos, y consiguiera asignarle un paquete a cada náufrago sin que uno solo envidie el paquete del otro, la distribución estaría lejos de ser considerada realmente equitativa. Supongamos que la distribución se hace sobre el conjunto de recursos x que contiene N's.
El problema surge cuando nos encontramos con algún náufrago al que no le gustan las N's, p.ej. el náufrago a. Así, aunque a no envidie el paquete de recursos de alguien más, porque todos los paquetes distribuidos contienen N's, sí podría reclamar con todo derecho que la distribución fue inequitativa, alegando que los recursos no son los que él mismo hubiese elegido de haber tenido la oportunidad.

La conclusión es que ambos tipos de procedimientos «mecánicos» no funcionan como medios para lograr una distribución equitativa. Ante este escenario, Dworkin propone un método diferente. El método más razonable para alcanzar una distribución de recursos que supere el test de la envidia es la subasta. Según este método, a cada uno de los náufragos se les dará un número igual de conchas (que se consideran sin valor de intercambio por su gran abundancia en la isla) para utilizarlo como medio de adquisición de recursos. ${ }^{11}$ Se hace una lista de lotes con cada uno de los recursos que se desean subastar, con la posibilidad de incluir cualquier otro recurso o parte de recurso en lotes distintos. Así, el que antes fue elegido para distribuir, y que ahora será el subastador, propondrá un precio a cada lote e irá ajustándolo según la demanda, hasta conseguir que el mercado se vacíe, esto es, que a cada lote le corresponda un comprador y no haya más lotes por subastar.

Si algún día se termina la subasta, y cada sobreviviente se declara satisfecho con el paquete de recursos que adquirió, entonces se puede aplicar el test de la envidia. El resultado sería que ningún náufrago debería envidiar el paquete de otro, dado que cada uno adquirió el paquete que deseaba, y siempre pudo adquirir el paquete que terminó en propiedad de alguien más. Y como aquí no ocurre lo de la selección arbitraria del conjunto de recursos a distribuir, porque cada uno pudo someter a puja el recurso que le interesaba adquirir, entonces este mecanismo de la

\footnotetext{
${ }^{8}$ En su propuesta, Dworkin (2000: 65s) explícitamente rechaza tratar con recursos públicos, incluyendo el problema de determinar cuál es la cantidad de poder que se ejerce (o debería ejercer) sobre ellos

${ }^{9}$ Estos matices son importantes. Que sean varios náufragos y no sólo uno es lo que obliga a pensar en la distribución; que en la isla existan recursos significa que hay algo que se puede adquirir y que no es imposible distribuirlo; que sean abundantes, aunque no ilimitados, es una condición necesaria para pensar en la distribución equitativa; que nadie humano haya en esa isla que reclame derechos de propiedad es lo que permite a los náufragos diseñar su propio modelo de distribución (de lo contrario, lo justo sería que los náufragos adoptaran al modelo de los nativos).

${ }^{10}$ La formulación original de este criterio de equidad se presenta como: «Ninguna división de recursos es una división equitativa si, una vez que se completa la división, algún inmigrante prefiere el paquete de recursos de alguien más a su propio paquete» (Dworkin 2000: 67). Este criterio de equidad no está libre de complicaciones y tampoco ha persuadido a todos de extender su alcance teórico. Hay incluso quienes, como Otsuka (2004: 72), piensan que este criterio todavía es insuficiente: «El test de la envidia no provee la definición completa de una distribución ideal. Ya que el test es compatible con un número indefinido de distribuciones [...] puede proporcionar únicamente una condición necesaria para una distribución ideal. Un sistema de libertad/constricción es parte de lo que se necesita para completar un conjunto de condiciones suficientes». Aunque esta alternativa de Otsuka al modelo original propuesto por Dworkin podría llevarnos por caminos interesantes, no hay espacio aquí para discutirla.

${ }^{11}$ Para que este modelo funcione, ciertas condiciones iniciales de igualdad deben ser satisfechas. Por ejemplo, ningún náufrago puede tener más conchas de las que tienen los demás, y tampoco se puede permitir que las pierda o se le arrebaten.
} 
subasta es equitativo y respeta las preferencias de cada persona.

Que no haya más recursos en la isla que N's, ya no es algo que se le tenga que reclamar a la subasta o al subastador, dado que eso es una cuestión de suerte (la mala suerte de llegar a una isla donde solo hay N's). Y que a todos les guste, o que todos deseen el mismo lote que uno, es una cuestión también de suerte (la mala suerte de tener preferencias o proyectos de vida comunes, que resultan, por ende, más costosos).

Un presupuesto básico de este modelo distributivo es que los náufragos conocen sus gustos, preferencias, proyectos de vida y capacidades, y en atención a ellos eligen los recursos que quieren y necesitan. Una teoría de la igualdad de bienestar tendría que ocultar esto tras un velo de la ignorancia. En cambio, una teoría de la igualdad de recursos configura un método de distribución tomando como base precisamente esa información. Por eso, afirma Dworkin, la subasta es «la métrica con la que se conoce el costo real de los recursos»: se sabe exactamente hasta qué punto ese recurso es importante para los demás y el costo que eso representa para el náufrago que lo adquirió.

\section{El nivel extendido}

Una distribución inicial equitativa de recursos, que es el «primer equilibrio» del esquema distributivo de Dworkin, no responde todavía a los problemas emergentes de una economía de mercado. El principal problema tiene que ver con el hecho fácilmente predecible de que: alguien que ha elegido por medio de la subasta un determinado paquete de recursos, no tiene garantizado con eso el incremento fijo de su riqueza ni el logro de su proyecto de vida.

Sin embargo, no es difícil estar de acuerdo con Dworkin cuando dice que de la información acerca de los recursos que se eligieron y del costo que representó adquirirlos, se puede hacer un cálculo aproximado del rendimiento que darán; es decir, hay una buena oportunidad de conocer las probabilidades de realización o de frustración del proyecto de vida elegido. Con esa información, las personas podrán hacer uso de los mecanismos propios del mercado para situar sus expectativas en una mejor posición.
A pesar de esto, no es falso que en una comunidad con una economía dinámica se puedan presentar factores que no hayan sido tomados en cuenta en el cálculo de esas probabilidades. ${ }^{12}$ Esos factores, según Dworkin, son: las habilidades (que haya náufragos más hábiles que otros en la producción de ciertos bienes «on demand»); los gustos (que haya náufragos que prefieran trabajar y otros que prefieran descansar, o dedicarse a la meditación); la salud (que haya náufragos más sanos que otros, o unos con discapacidades físicas o mentales, temporales o permanentes, y otros sin ellas); y las catástrofes (que haya náufragos a los que un incendio o un meteorito les arruine su paquete de recursos, mientras que a otros no). Ahora bien, las desigualdades que estos factores podrían producir se verán reflejadas en la cantidad de riqueza que los náufragos poseen. Al que es hábil trabajando es probable que le vaya bien en el comercio; en cambio, al que no tiene talento, es probable que le vaya mal; y la persona que prefiere descansar antes que trabajar es muy probable que se quede fuera de las negociaciones y pierda poco a poco sus recursos iniciales; y el que está enfermo no podrá realizar el trabajo por el que los otros le pagarían; y si la cosecha de alguien es arruinada por un incendio se quedará sin recursos con qué comerciar. A la larga, entonces, las desigualdades económicas entre unos y otros se incrementarán, y cuando se aplique el test de la envidia, muchos van a preferir el paquete de recursos de alguien más. ${ }^{13}$

La pregunta que tiene que responder ahora el esquema distributivo de Dworkin es, si es posible todavía, bajo estas variaciones de desarrollo económico y fortuna, la igualdad de recursos. Para contestar, Dworkin propone hacer una distinción entre suerte opcional y suerte bruta, a partir de la cual se podrá ubicar el margen de responsabilidad correspondiente. La suerte opcional (SO) tiene que ver con la decisión de correr algún riesgo con el cual se espera obtener algún beneficio (como en las apuestas), mientras que la suerte bruta (SB) tiene que ver con los riesgos que no son, en el sentido de la SO, decisiones deliberadas (como perder un brazo en un accidente de trabajo).

Con esta distinción, Dworkin diría que los cuatro factores de desigualdad (las habilidades, los gustos, la salud y las catástrofes), no son parte de una SO sino más bien de una $\mathrm{SB}$ - aunque no necesariamente en los mismos términos.

\footnotetext{
${ }^{12}$ Con la denominación «economía dinámica», Dworkin se refiere a prácticas comerciales e institucionales más complejas, es decir, aquéllas que rebasan el mero intercambio de recursos (como el trabajo, la inversión, el comercio, etc.).

13 Para que la modelo sea relevante para una sociedad dinámica, el test de la envidia debe aplicarse no sólo en la distribución inicial, sino de manera diacrónica, es decir, en cualquier momento posterior a la distribución inicial, sin una caducidad preestablecida.
} 
Es relativamente claro que uno no elije los gustos que tiene (aunque sí se puede decir que se desarrollan con base en ciertas elecciones previas), tampoco se decide la salud y las habilidades que se quieren tener, ni mucho menos se escoge el padecer o no alguna catástrofe. Esos factores, que Dworkin denomina «factores impersonales» se diferencian de los «factores personales» en la medida en que estos representan una elección o una posesión voluntaria, como decidir trabajar en algo provechoso o más bien darse el gusto de ir cada noche a un restaurante lujoso a tomar una copa de buen vino.

En nuestras sociedades, es común ver que las personas se aseguran contra la ocurrencia de ciertos «factores impersonales» para prevenirse de las consecuencias que producen. Por ejemplo, un pianista asegura sus manos ante el posible padecimiento de artritis, el dueño de una residencia la asegura por cualquier afectación que pudiese resultar de una catástrofe natural, etc. La moraleja aquí es que las personas pueden tomar la decisión de prevenirse contra alguno de esos riesgos. El seguro, en ese sentido, refleja las decisiones libres e informadas de las personas.

La idea del seguro es algo que Dworkin utiliza para vincular la SB con la SO, sobre la base de que prevenirse contra un daño fortuito tiene la forma de una apuesta, y esta la de una decisión deliberada de asumir o no un determinado riesgo. Para quien su proyecto de vida depende de preservar cierta habilidad física, un seguro contra el padecimiento de alguna discapacidad que afecte su actividad sería una decisión preventiva muy importante; y para quien su proyecto de vida depende del terreno que adquirió en la subasta, contratar un seguro para casos de inundación es una decisión preventiva impostergable. En todos estos casos, rige la idea de que los seguros que se contraten dependen en mayor medida del proyecto de vida elegido.

Tanto la decisión de contratar un seguro como el seguro en sí mismo pueden ser vistos como tipos particulares de apuesta. Que alguien contrate un seguro para el caso de que su taller de labrado se reduzca a cenizas después de un incendio, es apostar a que, si ocurre el incendio, la aseguradora se hará cargo de pagar según el nivel de cobertura estipulado en la póliza. Sin embargo, de no ocurrir ese incendio, el asegurado tendrá que seguir pagando la prima establecida en la póliza (lo cual representaría pérdidas económicas para él, porque esos recursos que destina a conservar el seguro podría destinarlos a la compra de herramienta o contratación de publicidad para su negocio, etc.) La diferencia entre quienes ganan o pierden en esas apuestas es lo que Dworkin considera como causas de desigualdad de riqueza. Quien apostó por un seguro de incendio y sufre el incendio estará en mejor posición económica con respecto a aquél que sufre un incendio y no se aseguró; y en una relación inversa con respecto a quien no contrata el seguro y no sufre el incendio. Lo que justifica esta desigualdad entre ganadores y perdedores es la afirmación no trivial de Dworkin de que "perder es el precio justo por la posibilidad de ganar».

Contratar un seguro representa una decisión igual de libre e informada que pujar por los recursos que se desean para la realización del proyecto de vida elegido. Privar a las personas de aceptar algunas apuestas es impedirles una elección libre y, con ello, frustrar sus proyectos de vida. Sin embargo, como Dworkin lo admite, puede haber buenas razones para evitar ciertas apuestas, por ejemplo, que las personas apuesten su vida, su libertad, sus derechos políticos, etc. Lo importante, después de todo, es que se respete el derecho de que el ganador reciba lo ganado y el perdedor asuma la pérdida. Repartir las ganancias entre el ganador y el perdedor conduciría a que nadie más quiera apostar, y si nadie más quiere hacer apuestas entonces en realidad nadie es libre de elegir sus proyectos de vida.

Con esto, sin embargo, solo se han mencionado algunos ejemplos de cómo la SO, mediante el mercado hipotético de seguros, se hace cargo de dos factores de la SB: la salud y las catástrofes. Por lo que todavía queda por ver cómo resuelve el problema de los gustos y las habilidades. La estrategia de Dworkin, al respecto, no es muy diferente a la anterior. Así como es posible contratar un seguro contra discapacidades y un seguro contra siniestros, Dworkin sostiene que también es posible contratar un seguro contra la falta de habilidades y un seguro contra los gustos caros.

El seguro contra la falta de habilidades funciona no de forma distinta al seguro contra discapacidades, porque en el se puede estipular que la falta de talento, por ejemplo; para jugar football, debe ser recompensada con un pago equivalente al nivel de ingreso que tendría, en este caso, un jugador talentoso de football (claro, con cargo a una póliza de seguro que subirá la prima tanto como suba la expectativa de ganancia). Por otra parte, el seguro contra gustos caros no es tan diferente del seguro contra siniestros. Quien tenga el temor de desarrollar un gusto 
$\tan$ oneroso como beber buen vino en un restaurante lujoso cada noche, podrá contratar un seguro que le recompense las pérdidas que sufrirá cuando su gusto esté efectivamente desarrollado. La necesidad de que una persona se asegure contra gustos caros es algo que tiene que ver con las pérdidas que sufriría cuando esos gustos le obliguen a perder los recursos que inicialmente obtuvo de manera equitativa en la subasta. Mientras los recursos iniciales le permitan satisfacer sus gustos, esa persona no envidiará el paquete de recursos de los demás. El caso contrario será cuando sus propios recursos se agoten, porque terminará por envidiar el paquete de los demás, aunque no por su contenido, sino por la posibilidad de que con ellos podría seguir satisfaciendo sus gustos caros.

\section{El nivel institucional ${ }^{14}$}

Aun cuando la distribución inicial de los recursos ha sido equitativa, y mediante los seguros se ha puesto un candado a las desigualdades causadas por los factores impersonales, el esquema distributivo de Dworkin no parece impedir que, dado el complejo funcionamiento de las economías dinámicas, surjan otras desigualdades originadas, por ejemplo, por las diferencias en los niveles de producción. Si no se impide a los náufragos un libre intercambio de bienes y servicios (laissez faire), es muy probable que aquellos que se dedican a la producción de bienes on demand terminarán en mejor posición económica para adquirir otros bienes que son del gusto, aunque no del alcance adquisitivo, de otros náufragos. Así, cuando se aplique el test de la envidia otra vez, será fácil encontrar náufragos que envidien el paquete de recursos de alguien más.

Para aceptar esta desigualdad y declararla no inequitativa, es necesario, según Dworkin, «ampliar» el concepto de envidia. La idea de que se envidie el paquete de recursos de alguien más no significa que se envidia solo los bienes que posee, sino también el tipo de vida (que, desde luego, incluye el proyecto de vida) que esa persona tiene. Así, cuando a una persona que dedica ocho horas al día al cultivo del maíz y seis horas a la contemplación del horizonte, se le pregunte si envidia el paquete de recursos de alguien que trabaja en la ciudad dieciséis horas al día en una oficina instalando software en dispositivos electrónicos, la respuesta probablemente sea que no. Todo dependerá, en última instancia, de si el agricultor tiene expectativas que solo se pueden realizar mediante la obtención de más riqueza, aun cuando con ello sacrifique su tiempo libre y la posibilidad de seguir contemplando el horizonte.

Lo que se intenta captar con esta ampliación del concepto de envidia es la idea de que las personas eligen autónomamente el proyecto de vida que quieren realizar y, a partir de eso, los recursos que necesitan para conseguirlo. La decisión de cultivar maíz o instalar software es previa al momento en que las circunstancias determinan cuál de las dos vidas será mayormente recompensada. Prever qué ocupación producirá más ganancias es algo que depende de la información acerca de los gustos y de las preferencias de otros náufragos, y esto es algo que se puede identificar en la elección de los recursos iniciales, es decir, en la subasta.

Al final, las desigualdades que se originan de esas decisiones no son injustas, y exigir compensación para aquellos que eligieron un proyecto de vida poco rentable representaría una interferencia inaceptable en la autonomía de las personas. En otras palabras, redistribuir la riqueza para preservar la igualdad de recursos está prohibido bajo la pena de contradecir los supuestos fundamentales de las condiciones de libertad y responsabilidad del esquema distributivo. ${ }^{15}$

Elegir autónomamente el proyecto de vida que se quiere realizar es una garantía de libertad que la IR de Dworkin parece conservar. Para eso, como se mencionó antes, el mercado hipotético de seguros considera no sólo las desigualdades originadas por discapacidad, sino también las que tienen su causa en los gustos caros, en las catástrofes y en el talento. Lo que falta por ver es cómo ajustar esa forma simple de aseguramiento en las instituciones político-económicas de una sociedad más desarrollada y, por lo tanto, más compleja.

\footnotetext{
${ }^{14}$ Es posible analizar la relevancia práctica del esquema distributivo de Dworkin en un nivel institucional porque (i) las condiciones teóricas de la subasta no son ajenas a ciertas estructuras económicas modernas, y (ii) la manera en que este esquema resuelve los problemas más sensibles de la justicia distributiva puede llevar a una evaluación crítica de las instituciones político-económicas reales, así como al diseño de otras formas institucionales.

${ }^{15}$ Con esta tesis, sin embargo, Dworkin no pretende justificar una teoría del «punto de partida» (starting-gate Theory). Es más, se aparta de ella (cfr. Dworkin 2000: 89). Una teoría del punto de partida defiende una adquisición de recursos justa y una distribución inicial equitativa, según la métrica que ella misma establezca, aun cuando después se deje llevar por laissez faire y permita cualquier tipo de desigualdad. Tal podría ser el caso de la propuesta de Nozick (1999). La IR de Dworkin tiene la ambición de aplicar la misma métrica inicial en cualquier momento futuro del comercio con la intención de asegurar no sólo una distribución inicial equitativa de recursos, sino también una comunidad liberal igualitaria.
} 
Sin entrar a detalle a la cuestión, se puede decir que el funcionamiento de las aseguradoras es más o menos equiparable al funcionamiento de las instituciones de asistencia pública, mientras que el cobro de primas de los seguros contratados (que varían según el nivel de cobertura estipulado en la póliza) es el equivalente a los impuestos (particularmente al impuesto sobre la renta o ISR). Así, en lugar de esperar que los náufragos desarrollen sentimientos morales de empatía y caridad, podemos obligarlos a que pongan algo de su riqueza en un fondo común de asistencia pública (que será la base sobre la que se otorgarán las compensaciones para aquellos que sufran de alguno de esos factores impersonales de afectación).

La razón de que se obligue a todos los náufragos y no solo a unos cuantos a pagar un ISR consiste en que todos ellos estarían dispuestos a contratar un seguro para prevenirse contra algunos (o, al menos, los más comunes) de esos factores impersonales. La decisión de contratar un seguro es una apuesta que favorece a quienes sufren un daño, $y$, en cierto modo, también a quienes no lo sufren: estos se verían obligados a llevar a cuestas las pérdidas de los demás, si no fuera porque ellos mismos habrían asumido libremente el compromiso de pagar una prima para asegurar su nivel económico.

Desde luego, así como la prima del seguro varía según el tipo de seguro contratado y el nivel de cobertura elegido, así también varía el tipo impositivo que se cobrará a los náufragos. Por ejemplo, quienes sean más propensos a sufrir ciertos daños o los que tienen expectativas de riqueza muy alta, pagan una prima mayor que aquellos que están en una situación contraria. De ahí que Dworkin acepte que los impuestos varíen según el nivel de riqueza que cada persona posee.

\section{Autonomía y responsabilidad}

Con esta distinción en niveles, debería tenerse ya una idea general del esquema distributivo de la IR de Dworkin. Del modelo hipotético, se ha destacado el test de la envidia como criterio de distribución equitativa, y la subasta como medio de elección y adquisición de los recursos y seguros que se desean. Del nivel extendido, se han expuesto algunas de las complicaciones que la SB impone al modelo inicial de distribución, y la manera en que el mercado hipotético de seguros las enfrenta. Por último, del nivel institucional, se ha mencionado la forma en que ese mecanismo de aseguramiento se puede traducir en prácticas institucionales reales, como el ISR. Ahora conviene enfocarse con mayor atención en dos supuestos fundamentales de ese esquema distributivo: la autonomía individual y su consecuente atribución de responsabilidad.

Dworkin no define el concepto de persona en su esquema distributivo, aunque sí menciona algunas características importantes. Por ejemplo, se trata de sujetos libres y autónomos, con preferencias y actitudes particulares. ${ }^{16}$ Bajo esta caracterización, Dworkin parece tomar cierta distancia del concepto de persona que estipula Rawls (1984: 12s) en su teoría de la justicia como imparcialidad. En Rawls, la persona es un sujeto autónomo racional que posee alguna concepción del bien y sentido de la justicia. Estas últimas dos propiedades son necesarias para el propósito general de Rawls, esto es, justificar principios de justicia que sirvan de trasfondo a la estructura básica de una sociedad democrática avanzada. Para Dworkin, en cambio, los principios de justicia distributiva están claramente determinados (uno es el principio de igual importancia, y el otro es el principio de responsabilidad especial), y a partir de ellos se van a definir los mecanismos y procedimientos mediante los cuales se logrará una distribución inicial equitativa, y se sostendrá una comunidad liberal igualitaria. ${ }^{17}$

En el esquema distributivo de Dworkin, como se ha visto ya, los náufragos son quienes eligen los recursos que desean obtener según el proyecto de vida que pretenden realizar. Y esa elección de recursos, como también se ha visto, se hace mediante la puja en una subasta de recursos y seguros. Lo que se debe ver ahora es que, para llevar a cabo esa elección, los náufragos deben cumplir, por lo menos, dos condiciones: poseer un proyecto de vida y tener la capacidad de identificar que son unos y no otros los recursos que les permitirán realizar ese proyecto de vida. La primera condición implica poseer una cantidad suficiente de información sobre lo que significa optar por un proyecto de vida y los merecimientos que ese proyecto otorga; la segunda condición implica, por una parte, el conocimiento de los recursos que son necesarios para la realización del proyecto deseado, y por otra parte,

\footnotetext{
16 Dworkin (2000: 69, 140).

17 De manera al menos superficial, se podría decir que Dworkin y Rawls comparten una concepción kantiana de persona. Una concepción que sirve para justificar un modelo de libertad e igualdad ajeno a compromisos ideológicos irreconciliables (o lo que Rawls llama doctrinas comprehensivas del bien).
} 
un comportamiento racional basado en la obediencia a ciertas reglas del cálculo. Este comportamiento racional expresa un tipo específico de conexión normativa: la elección informada obliga a actuar en consecuencia; es decir, a reconocer el deber de asumir las cargas de la elección. Este es un aspecto importante en el desarrollo del argumento que aquí presento, y volveré a el más adelante.

Rawls defendía que los agentes morales racionales solo pueden construir acuerdos sobre la base de sus propios intereses y en condiciones genuinas de igualdad y libertad, fuera de toda coacción, engaño, imposición, fraude, etc. ${ }^{18}$ Dworkin también piensa estas condiciones como indispensables para que una persona pueda decidir qué proyecto de vida realizar y ser considerado responsable de esa decisión. Para ambos, la satisfacción de esas condiciones es lo que define a las personas como agentes autónomos. La autonomía, cabe aclarar, no expresa por sí misma una posición política particular diferente del liberalismo igualitario que a Dworkin le interesa defender.

Cuando una persona está al tanto de las posibilidades que tiene enfrente y es libre para elegir la que mejor le parece, entonces excluye cualquier razón para negar su responsabilidad por la decisión que ha tomado. Por supuesto, llenar de información a una persona no es cosa fácil, y la propuesta de Dworkin no intenta solucionar este problema. El argumento que aquí se propone para atribuir responsabilidad sobre la base de ambas premisas (información y elección libre) tiene la siguiente forma lógica. Sea el caso, que una persona no cuenta con información suficiente para reconocer que hay más de una posibilidad de elección. Ahora, como el mismo concepto de elección supone esa posibilidad, la decisión de esa persona no es una verdadera elección. Sea además el caso que la responsabilidad se atribuye solo por aquellas decisiones que son tomadas sobre la base de elecciones genuinas (lo cual es equivalente a decir que, o no se puede atribuir responsabilidad, o se garantiza una elección genuina). Por lo tanto, es una condición necesaria para la atribución de responsabilidad dotar a la persona con información suficiente para reconocer las diferentes posibilidades de elección.

Si ya se eligió el proyecto de vida, el siguiente paso es elegir los recursos que se necesitan para llevarlo a cabo. La subasta garantiza la libertad de las personas para elegir, según ese proyecto de vida, los recursos adecuados; además, permite conocer el costo que representa para los demás esa elección. Y como en ese escenario de elección también se decide contra qué factores impersonales prevenirse, la distinción que hace Dworkin entre SB y SO es fundamental: que sea una elección prevenirse contra una catástrofe, o contra el padecimiento de cierta enfermedad, o contra la falta de talento para realizar una empresa particularmente valiosa, significa acercar la ocurrencia de un hecho impersonal (des)afortunado a las condiciones necesarias para atribuir responsabilidad individual. Y que esa prevención se manifieste mediante un contrato de seguro, libre y voluntario, es una alternativa que expresa la importancia que se concede, según el alcance del proyecto de vida, a ciertas facultades físicas y mentales, así como a los recursos elegidos.

Ahora bien, con base en el argumento para la atribución de responsabilidad, para que la decisión de contratar un seguro sea considerada una elección libre, tiene que ser también una elección informada. Esto presupone la posibilidad de que las personas puedan conocer anticipadamente el futuro, es decir, que sean capaces de prever que algunos hechos pueden ocurrir con mayor o menor probabilidad, o que las ventajas de un proyecto de vida pueden ser mayores o menores en tanto predominen un cierto estado de cosas. Esta capacidad de previsión tomará un valor objetivo importante en tanto se reconozca el vínculo normativo de actuar en consecuencia como resultado de la elección, esto es, como la responsabilidad de asumir los costos de la elección y hacerse cargo de las consecuencias desfavorables (aún si ellas se deben a la intervención de más de un factor personal o impersonal, o a la intervención de otros agentes). ${ }^{19}$

La responsabilidad por haber elegido un proyecto de vida poco rentable o de haber elegido mal los recursos para llevarlo a cabo se traduce en la imposibilidad de reclamar

\footnotetext{
De ahí que Dworkin imponga cualidades racionales en sus náufragos tanto como Rawls las exigía para los agentes morales que participan en su posición originaria. La diferencia entre ellos estaría entonces en que Dworkin defiende un mecanismo de distribución sensible a las ambiciones de esas personas, mientras que Rawls las oculta tras el velo de la ignorancia.

18 Rawls (1984: 12-16).

${ }^{19}$ Gracias a esto es que Scheffler (2003: 199-201) dice de la IR de Dworkin, que incorpora algo así como una «igualdad de fortuna» (Luck Egalitarian). Cuáles son las consecuencias de esto, en caso de ser correcto, no es algo que se pueda discutir a detalle aquí. Sin embargo, es un buen ejemplo de que la noción de igualdad que emplea Dworkin en su esquema distributivo parece abarcar mucho más que solo recursos.
} 
una redistribución de recursos según el esquema distributivo de Dworkin, es decir, cuando alguien es considerado responsable por su decisión (por ejemplo, contratar o no un seguro contra discapacidad, o haber adquirido en la subasta ciertos bienes y no otros, o elegir ser un jugador de fútbol y no un instalador de software, etc.) significa que no hay una razón para activar el derecho a demandar del Estado una justa redistribución de los recursos disponibles.

Es preciso detenerse un momento aquí. No hace falta mucho esfuerzo para reconocer que el concepto de responsabilidad que emplea Dworkin no satisface una definición unívoca. No obstante, la fuerza de su IR depende en cierta medida de la manera en que se pueda entender (y usar) ese concepto. Por ejemplo, no es lo mismo pensar que la responsabilidad de una acción tiene que ver exclusivamente con las intenciones del agente, que si se piensa como incluyendo también acciones nointencionales. En una concepción caben menos casos que en otra. Por ejemplo, si se admite que la responsabilidad de un sujeto se expresa en la elección de asegurarse o no asegurarse contra la pérdida de la vista, ¿qué nivel de responsabilidad sería justo atribuir a una persona que, frente a la elección de adquirir el seguro, sin reflexionar al respecto, decide no hacerlo porque sus demás colegas no lo hicieron?

El esquema distributivo de Dworkin, bajo una interpretación de la responsabilidad que incluya acciones no-intencionales como esta, no negaría la responsabilidad de esa persona por no haber adquirido el seguro. De modo que, aun contra los alegatos de algunas posturas comunitaristas, la decisión de no adquirir el seguro contra la pérdida de la vista simplemente por influjos o constreñimientos del entorno social, no exigiría del esquema distributivo de Dworkin compensación alguna. ${ }^{20}$

Para entender qué posición es más coherente con el esquema distributivo de Dworkin, es necesario aclarar su noción de responsabilidad. De acuerdo con los argumentos que se presentarán a continuación, se puede sostener que la noción de responsabilidad que emplea Dworkin es consecuente con la noción defendida por Hart (2009). Según este, la noción de responsabilidad tiene cuatro sentidos: rol, causal, obligación (liability) y capacidad. ${ }^{21}$ En el primer sentido, la responsabilidad de una persona se atribuye en virtud de la posición o el rol que desempeña (y las funciones u obligaciones que le corresponden). En el segundo, la atribución de responsabilidad tiene que ver con la participación que tiene esa persona dentro de la línea causal que representa la conexión entre una acción u omisión y sus resultados (dejando espacio para los problemas de responsabilidad objetiva). ${ }^{22}$ En el tercer sentido, la responsabilidad de una persona se establece con base en el reconocimiento de ciertas características o propiedades que la convierten en un agente, las cuales se identifican de acuerdo al ámbito de atribución (por ejemplo, moral o jurídico). Finalmente, en el cuarto sentido, una persona se considera responsable de cierta acción u omisión en tanto satisfaga ciertas condiciones o reúna ciertas capacidades.

Boxer (2014: 36) distingue en estos sentidos de

\footnotetext{
20 Según Kymlicka (2004: 113), hay dos caminos para el ataque comunitarista a esta versión de la IR: «algunos comunitaristas critican a los liberales por exagerar el valor de la libertad de elección; otros aceptan la importancia de la libertad de elección, aunque critican a los liberales por descuidar las precondiciones sociales que la hacen posible». Kymlicka elige el segundo camino, aunque me parece que su reclamo adquiere mayor sensibilidad desde la noción de responsabilidad (no desde la noción de libertad): «sabemos que algunas personas no manejarán bien las decisiones que la vida requiere. Cometerán errores acerca de su vida, eligiendo hacer cosas triviales, degradantes, e incluso dañinas. Permitirles a esas personas libertad de elección, parece no un acto de respeto sino de indiferencia, abandonándolos a un destino predeciblemente infeliz. ¿Por qué no deberíamos intervenir y prevenir a las personas de cometer tales errores?» Como intentaré mostrar más adelante, la noción de responsabilidad incluida en el modelo de la IR de Dworkin no es ajena a este reclamo. Es más, bajo cierta interpretación, puede incluso dar una respuesta favorable. Hay, sin embargo, un detalle importante en esta crítica que no podré discutir en este trabajo. De acuerdo con Kymlicka (2004: 114), «Dworkin necesita libertad de elección precisamente porque podemos estar equivocados, y la libertad nos ayuda a hacer las cosas bien. [Dworkin] desarrolla una curiosa y sofisticada defensa de la libertad, basado en un modelo de elección de revisión racional». Este modelo, que explicaré con más detalle más adelante, supone ajustar las decisiones personales a las creencias, y examinar o cuestionar esas creencias a la luz de cualquier información disponible. La crítica que quiere hacer Kymlicka a esta respuesta de Dworkin consiste en que la base para esa capacidad de revisión racional ya supone un ambiente social con condiciones aptas para su ejecución, así como alternativas de elección limitadas a ese mismo contexto. Esto conduce, en último término, a una especie de circularidad al interior de la IR. Para contestar esta objeción, me parece necesario tomar en cuenta las condiciones para el desarrollo de ciertas capacidades. Algo que, aunque crucial para cualquier teoría de la justicia (liberal, comunitarista, etc.), no puede detener el debate acerca de los modelos de distribución de recursos y las condiciones de atribución de responsabilidad.

${ }^{21}$ De acuerdo con Boxer (2014), la responsabilidad entendida como obligación (liability), tiene, a su vez, dos acepciones. Por un lado, la obligación moral (moral liability), y, por el otro, la obligación jurídica (legal liability).

22 La responsabilidad objetiva (strict liability) representa muchos problemas para la noción general de responsabilidad. Con esa denominación se habla de casos en los que no hay causa, no hay intención y quizás tampoco hay estado mental normal, a pesar de lo cual, sin embargo, se atribuye responsabilidad, es decir, se exige una respuesta o compensación por los daños provocados. Los objetivos de este trabajo no requieren detallar más la discusión, a pesar de la gran importancia que tiene ese concepto en la filosofía moral y jurídica contemporánea.
} 
responsabilidad, aunque de manera no exhaustiva sino solo explicativa, tres condiciones: (i) entender lo que requiere el deber, (ii) deliberar y tomar decisiones respecto de ese requerimiento, y (iii) actuar de conformidad con esas decisiones. A estas condiciones se les puede denominar capacidad de entendimiento, capacidad de razonamiento y capacidad de autocontrol, respectivamente. Admitir la satisfacción de esas capacidades refuerza la eficacia de las reglas de operación de la práctica social en la que estemos participando (en la obra de Hart, esa práctica social es el derecho). La culpa o reproche que asigna esa práctica social, por el contrario, se debilita ante la ausencia de esas capacidades. $^{23}$

Los supuestos fundamentales del esquema distributivo de Dworkin parecen seguirse de este último sentido de responsabilidad que caracteriza Hart, esto es, responsabilidad en el sentido de satisfacción de capacidades. Para demostrarlo, es suficiente con mencionar algunas de las ideas expuestas anteriormente. Una persona es responsable de las decisiones que toma en la medida en que cuenta con información relevante suficiente, tiene la capacidad de revisar sus propias creencias, ${ }^{24}$ y reconoce el deber racional que esa elección conlleva. A falta de esas capacidades sería difícil sostener (o justificar) la atribución de responsabilidad, al menos tomando como base de esa atribución la autonomía de la elección.

Esas capacidades que se han reconocido en el esquema distributivo de Dworkin determinan entonces la autonomía de la persona y representan, según se verá a continuación, las capacidades básicas mínimas que deben asegurarse de manera universal. Por supuesto, asegurar esas capacidades representa un compromiso de deber por parte del Estado, que tendrá la obligación (y por tanto una responsabilidad, en el tercer sentido hartiano) de proveer escenarios adecuados de satisfacción. Escenarios en los cuales tiene sentido hablar de proteger ciertas condiciones, por ejemplo, salud, alimentación, educación, cultura, ciencia, etc.

En otras palabras, la carga que impone la atribución de responsabilidad, siguiendo este modelo de análisis hartiano, es lo que nos permite pensar la IR de Dworkin en términos de capacidades: porque lo único que exime al esquema distributivo de compensar desigualdades es el hecho de que las personas no sean responsables de las consecuencias que sus decisiones originan. Y para que sean responsables, como se sigue del argumento ofrecido anteriormente, sus decisiones tienen que ser libres e informadas. Y si para elegir con plena libertad y en posesión del conocimiento relevante es necesario satisfacer ciertas condiciones mínimas, entonces es posible pensar en un punto más básico de igualdad. Uno que podríamos interpretar como igualdad de capacidades básicas. ${ }^{25}$

\section{Igualdad de capacidades}

Con lo dicho hasta ahora, ya se puso en claro que a Dworkin le interesa dar cuenta de la influencia que tiene el azar o la SB en las condiciones de atribución de responsabilidad individual, es decir, en las razones que colocan a una persona en posición de ser compensada o no por las consecuencias originadas por los factores impersonales de afectación. Esto se puede ver como un distanciamiento entre las condiciones de autonomía del esquema distributivo de Dworkin y el principio de diferencia de Rawls, que solo admite redistribuciones cuando son en beneficio de la clase menos aventajada ( $\sin$ importar el origen de esas desventajas $)^{26}$. Lo relevante ahora es mostrar que este sentido de responsabilidad que incorpora Dworkin implica una noción amplia de igualdad de capacidades que no es inconsistente con el principio regulativo de la IR, esto es, el principio de tratar a las personas con igual consideración. Lo que significa reconocer que los intereses de cada miembro de la comunidad importan y se valoran en igual medida.

De acuerdo con el esquema distributivo de la IR, el peso de los intereses de cada persona, expresados mediante decisiones autónomas, recae en quien toma la decisión y no en quien es ajena a la deliberación. La responsabilidad que está detrás de esta tesis no es solo de carácter político o jurídico, sino básicamente de carácter moral, de ahí que el contenido de la responsabilidad individual este determinado por principios morales.

\footnotetext{
25 Hausman (2009) usa el término «libertades básicas» para referirse a lo mismo, y lo pone como una respuesta incluyente de la versión de Dworkin.

${ }^{26}$ De acuerdo con Cohen (2004: 31), «Dworkin quiere arreglar la teoría de Rawls: busca una versión de justicia distributiva insensible a las dotaciones (endowment-insensitive). Igual que Rawls, él cree que las dotaciones naturales son arbitrarias desde un punto de vista moral. Sin embargo, Dworkin opina que las desigualdades naturales de las dotaciones, incluyendo las diferencias en habilidad que producirían diferencias en el ingreso, deberían ser compensadas; mientras que Rawls no piensa la justicia en términos de compensación: el principio de diferencia no se dirige al equilibrio de compensación (balancing compensation). Además, Dworkin cree que las diferencias de ingreso que reflejan diferencias en la preferencia y elección no deberían ser reducidas: una distribución justa debería ser sensible a las ambiciones (ambition-sensitive)».
} 
Esos principios morales son también el fundamento del esquema distributivo de Dworkin. Solo así se entiende la exigencia de tratar con respeto la decisión individual de qué proyecto de vida realizar. En este caso, hay un principio de fondo que nos obliga a tratar con igualdad la forma de vida que los demás eligen, sin coaccionar o limitar sus preferencias e intereses. En todo caso, y esto es lo que importa, el que una persona elija un tipo de vida y decida llevarlo a cabo, le impone la obligación de hacerse cargo de los resultados que obtenga y beneficiarse o asumir los costos que de ellos se deriven.

Este hacerse cargo es, al mismo tiempo, una expresión de la aceptación del compromiso de autonomía individual. Por supuesto, alguien que no crea haber sido tratado con igualdad no permitirá que no se le compense por las consecuencias que sus decisiones originen. $\mathrm{Y}$ ese tratar con igualdad a las personas supone un cierto equilibrio de las capacidades que ellas poseen para alcanzar su autonomía. Sólo así es posible pensar la IR de Dworkin como una propuesta liberalista genuinamente igualitaria.

Sin embargo, ¿cómo dar cuenta de las capacidades de entendimiento, razonamiento y autocontrol en la versión de la IR de Dworkin, sin alterar su objetivo fundamental, es decir, que la libertad que importa está en la distribución de recursos? Ya dijimos que con el esquema distributivo de Dworkin lo que se busca igualar son los recursos disponibles, es decir, que todos tengan en igual medida los recursos que necesitan (y desean) para materializar el proyecto de vida que eligieron realizar. Sen (1992: 53s) va a discutir esta interpretación de la igualdad que propone Dworkin para enfatizar que lo que realmente importa no es igualar recursos, que son a fin de cuentas solo medios, sino igualar las capacidades, que son las que condicionan la importancia de los medios. Este es el reto que tiene que enfrentar ahora la propuesta de Dworkin.

Según la igualdad de capacidades (IC) de Sen, que todos tengan la posibilidad de hacer, pensar, ver, escuchar, etc. es lo que los hace libres. Dworkin, en esto, no estaría en desacuerdo, principalmente porque esa libertad a la que se refiere Sen es una libertad de elección. ${ }^{27}$ En tanto que una persona posee la capacidad de ver, puede elegir un proyecto de vida que requiera el funcionamiento de esa capacidad, por ejemplo, ser piloto aviador. Ese tipo de capacidades representan entonces una condición necesaria para que la persona pueda elegir el proyecto de vida que realmente desea, según sus propias preferencias e intereses. ${ }^{28}$

Esa posibilidad de elección, que se amplía o se reduce según las capacidades que se poseen, es condición necesaria, como se mencionó en el argumento sobre la atribución de responsabilidad, para tomar una decisión autónoma. La restricción de esa elección supondría la no satisfacción de esa condición y, en consecuencia, la no autonomía de la decisión; de lo cual se seguiría, por obversión lógica, que la persona no sea responsable de los resultados que esa decisión produzca. De ahí que, de acuerdo con la IR de Dworkin, esa persona sea merecedora de alguna compensación.

Cabe aclarar que la IC de la que quiere hablar Sen, y la única que aceptaría Dworkin, es una que se preocupa no porque todas las personas hagan de hecho lo mismo, sino porque todas tengan la posibilidad de hacer lo mismo. Se trata, pues, de una posibilidad que nos permite imaginar la realización de los proyectos de vida que se desean, para luego elegir entre uno u otro. Así, a mayor amplitud de alternativas corresponde mayor libertad de elección. Sin embargo, esa libertad, como lo señala Hausman (2009: 751), es coincidente con la versión de la IR de Dworkin: la libertad define los contornos del igualitarismo y los límites de la responsabilidad, en tanto que (i) todos deben tener garantizado un vector de libertades básicas, incluyendo las condiciones sociales, habilidades y competencias para hacer uso de ellas; y (ii) esta preocupación por la libertad no debería ir más allá de (a) garantizar esas libertades básicas, (b) expandir el rango de alternativas entre las cuales las personas pueden optar, y (c) ayudar a las personas a adquirir mayores capacidades en la elección. ${ }^{29}$

\footnotetext{
${ }^{25}$ Es más, Sen (1992: 50ss) defiende que ésa es la clase de libertad que realmente importa.

${ }^{26}$ Dworkin rechaza que la IC sea una teoría realmente diferente, o a la igualdad de bienestar (IB), o a la IR (y en esto consiste su acusación de que la noción de capacidades es ambigua). Se aproxima a la IB en tanto que las capacidades importan para la satisfacción de ciertas preferencias, y condena entonces la desigualdad sólo porque hay preferencias más caras que otras. En cambio, se aproxima a la IR cuando las capacidades se ven como recursos y se decide el aseguramiento de unas u otras, de acuerdo con el proyecto de vida elegido. En este trabajo, desde luego, estoy siguiendo la segunda interpretación. La formulación de la crítica de Sen y la respuesta de Dworkin pueden verse en Williams (2002) y en Dworkin (2002: 136-140).
} 
El igualitarismo que surge de esa concepción de la libertad es lo que Roemer (1993: 147) nombra «igualitarismo ético». Un caso especial de igualitarismo que consiste en que «la sociedad debe indemnizar a las personas en contra de los malos resultados que son consecuencias de las causas que están más allá de su control, [aun si no lo hace] en contra de los resultados que son las consecuencias de las causas que están dentro de su control, y por lo tanto, por las cuales son responsables personalmente». ${ }^{30}$ Precisamente esta es la clase de libertad que Dworkin parecería estar dispuesto a defender en su IR. Una libertad negativa, sujeta a ciertos constreñimientos, que permite hablar con todo sentido de responsabilidad personal. Esta afirmación es consecuente incluso con la forma en que el mismo Dworkin resuelve el conflicto entre libertad e igualdad: «si aceptamos la igualdad de recursos como la mejor concepción de la igualdad distributiva, la libertad será un aspecto de la igualdad más bien que, como a menudo se ha creído, un ideal político independiente con quien está potencialmente en conflicto». ${ }^{31}$

La tesis que aquí se quiere sostener se sigue de esta noción de libertad que protege la IR de Dworkin. Una noción que se puede traducir en el lenguaje de los derechos, siempre que se entienda que «las concepciones dominantes de la libertad en nuestra comunidad política tienen esta estructura general: no protegen las libertades como una autorización (license) sino como un conjunto de derechos diferenciados para libertades particulares». ${ }^{32}$ Así, la libertad de elección se traduciría como un derecho a la libertad de elegir. Y es importante esta traducción, porque hablando de derechos se puede hablar de obligaciones; en este caso, la obligación que corresponde al aparato institucional del Estado para corregir las deficiencias o interferencias que limitan o impiden el ejercicio de ese derecho. Y cuando se habla de obligación, como se mencionó anteriormente, se puede también hablar de responsabilidad (al menos, en el tercer sentido que propone Hart).

En consecuencia, bajo esta concepción de la libertad, las personas podrían reclamar del Estado una mejor posición social, cultural, educativa, ambiental, de salud, etc. en tanto que eso eliminaría las deficiencias o interferencias que pueden provocarles no ejercer con toda conciencia y plena capacidad sus derechos de libertad de elección (es decir, su elección libre e informada de recursos). Por tanto, así entendida, habría una igualdad de capacidades contenida en el alcance de las condiciones necesarias del esquema distributivo de la IR de Dworkin.

Ahora bien, ya se dijo que el trato igualitario, o la virtud soberana de Dworkin, es el principio regulativo de la IR, y que es este el que fija el valor o la importancia de la libertad. Y se dijo también que el esquema distributivo, por medio de una concepción amplia de responsabilidad, asegura la libertad individual de las personas con respecto a su elección del proyecto de vida y su elección de los recursos que quieren y necesitan para llevarlo a cabo, y que en caso de que esas condiciones no sean satisfechas, será justo esperar de las instituciones político-económicas una compensación en términos de redistribución. De igual forma, se acaba de decir que, según la noción traducida del igualitarismo ético, las personas tienen garantizado el derecho de libertad de elección, al cual corresponde la obligación del Estado de garantizar un escenario viable para su pleno ejercicio. Esto, sin embargo, no representa una interferencia paternalista sino una efectiva participación del aparato institucional del Estado para favorecer las exigencias igualitaristas del modelo liberal de la IR. Lo que falta por decir es que el esquema distributivo de Dworkin, que incluye esa exigencia de capacidades mínimas, es consistente con el principio regulativo de la IR.

La IR, como bien lo concluye Pereira (2004: 194), tiene que ser "entendida como una teoría que asegura un conjunto [no particular o específico] de capacidades básicas mínimas, conjuntamente con una distribución de medios sensible a la ambición, el esfuerzo y las elecciones individuales». Que haya agregado a esta cita que ese conjunto de capacidades básicas mínimas no

\footnotetext{
${ }^{29}$ Hausman (2009: 751) agrega al umbral de no-responsabilidad que «[otras] desigualdades más que las desigualdades en las libertades básicas llaman a la compensación si y solo si son resultado de desigualdades en el rango de alternativas entre las cuales las personas pueden optar, o desigualdades en la competencia para tomar elecciones». Ahora, si se tradujeran los puntos (i), (ii), y esta última inclusión de Hausman a un lenguaje de intereses políticos, se podría decir entonces que la versión de Dworkin no está tampoco lejos de la teoría de la igualdad de capacidades de Nussbaum (cfr. Nussbaum, 2006: 155). Dejo, sin embargo, para otro momento el desarrollo de esta idea.

${ }^{30}$ Roemer (1993) acepta, en principio, este igualitarismo ético de la IR. No obstante, su proyecto se extiende a la búsqueda de una noción de igualitarismo político, que tenga como justificación no una formulación conceptual sino una abstracción de diferentes situaciones prácticas. Para conseguirlo, discute la igualdad de bienes primarios de Rawls, la IR de Dworkin, la IC de Sen, la igualdad de oportunidades de bienestar de Arneson, y la igualdad de acceso a las ventajas de Cohen. Por esta razón, su proyecto es más ambicioso del que aquí se propone.

31 Dworkin (2000: 121).

32 Dworkin (2000: 127).
} 
está especificado, responde a la demanda misma de revisabilidad. Es decir, si se estipula de antemano qué capacidades se deben satisfacer y no se deja espacio para una nueva formulación, entonces se estaría negando la exigencia de revisión de creencias que se asumió como una propiedad de la autonomía de las personas. Aunque parece ser importante trabajar en la elaboración de una lista amplia de esas capacidades, no es ese el objetivo principal de la IR, y ni siquiera de la IC (de Sen). A lo más, los ejemplos de capacidades mínimas que se mencionaron aquí pueden servir como una pequeña muestra de los impulsos igualitaristas que defienden una genuina libertad en términos de autonomía.

¿En qué sentido son consistentes esta igualdad de capacidades mínimas y el principio regulativo de la IR de Dworkin? Bien, lo que parece importarle a Dworkin es conseguir que el Estado trate con igualdad a las personas; una igualdad que significa no interferir en sus gustos, ambiciones o expectativas de vida. Igualdad que también significa compensarles por todos aquellos casos en los que los factores impersonales afectan sus proyectos de vida. Donde esa compensación se determina según una noción amplia de responsabilidad: mientras que la persona sea responsable de sus decisiones, el Estado no estará justificado en redistribuir los recursos para preservar la igualdad de riqueza. Y si lo determinante entre las dos posibilidades de compensación y nocompensación es la responsabilidad, entonces no puede negarse que hay alguna razón por medio de la cual se atribuye esa responsabilidad (a falta de la cual, hacerlo es inaceptable o injusto). Si esa razón significa la satisfacción de las condiciones mínimas de autonomía, entonces hay que buscar la manera de hacer que las personas cumplan con esas condiciones. Y como estas condiciones no son satisfechas hasta que las personas se encuentren en un escenario óptimo de realización, su libre elección se vuelve un derecho a la libertad de elección que impone, de manera correlativa, una obligación al Estado de asegurar en la mayor medida posible las posiciones que más favorezcan a su libre ejercicio: mejoras en la salud, buen ambiente, desarrollo cultural y científico, educación de calidad, etc

\section{Conclusiones}

Del supuesto de que las personas son autónomas, y por eso mismo responsables de sus propias decisiones, se sigue la obligación de tratarlas con igual consideración y respeto. Lo cual no significa proporcionales continuamente lo que necesitan, sino eliminar las desigualdades económicas que surgen de los factores impersonales de desigualdad y mantener una distribución equitativa de recursos (que siempre son escasos y limitados). Una distribución, en otras palabras, que sea sensible a las ambiciones de los individuos, que se logre mediante mecanismos liberales de distribución (como la subasta y el mercado hipotético de seguros), y que en la práctica sirva para diseñar instituciones político-económicas, es decir, para construir una comunidad liberal igualitaria.

Con el esquema distributivo de la IR, las personas son responsables de las decisiones que toman, siempre que lo hagan de manera autónoma y cuenten con la información relevante suficiente. Si estas condiciones no se satisfacen, entonces esas personas podrán exigir con todo derecho una redistribución de los recursos (o de la riqueza que otros poseen) para compensar su situación. La manera de llevar a cabo esa redistribución se ajusta a los resultados del mercado hipotético de seguros traducido en los sistemas económicos institucionalizados, como políticas públicas y cargas tributarias.

Asimismo, en la medida en que el Estado tiene la obligación de asegurar el cumplimiento del derecho de libertad de elección de las personas, estas podrán reclamar el mejoramiento de su situación social, económica, cultural, etc. La base para esta reclamación se encuentra en las condiciones necesarias para el ejercicio de ese derecho: ejercer con plenitud el derecho de elección entraña las capacidades mínimas necesarias para procesar la información que se tiene y reconocerse libre dentro de las circunstancias particulares.

Con todo lo dicho en este trabajo, es posible defender la tesis de que la IR de Dworkin no es incompatible con la IC de Sen. Por el contrario, bajo la interpretación que aquí se ofrece, la propuesta de Dworkin parece incluso abrir camino a los planteamientos más específicos del proyecto igualitarista.

\section{Referencias}

1. Arneson, R. (2004). Cracked Foundations of Liberal Equality. En Dworkin, R. y Burley, J. (Ed.) Dworkin and his Critics. With replies by Dworkin (pp. 79-98). Blackwell Publishing, London.

2. Boxer, K. (2004). Hart's Senses of Responsibility. En Pulman, C. (Ed.) Hart on Responsibility (pp. 30-46). 
Palgrave Macmillan, London.

3. Brown, A. (2009). Ronald Dworkin's Theory of Equality. Domestic and Global Perspectives. Palgrave Macmillan, London.

4. Cohen, M. (2004). Talent, slavery, and envy. En Dworkin, R. y Burley, J. (Ed.) Dworkin and his Critics. With replies by Dworkin (pp. 30-44). Blackwell Publishing, London.

5. Dworkin, R. (2000) Sovereign Virtue. The Theory and Practice of Equality. Harvard University Press, London.

6. (2003). Equality, Luck and Hierarchy. Philosophy and Public Affairs, 31(2), 190-198. doi: doi. org/10.1111/j.1088-4963.2003.00190.x

7. (2002). Sovereign Virtue. Revisited. Ethics, 113(1), 106-143. doi: 10.1086/341579

8. (2006) Is Democracy Possible Here? Principles for a new Political Debate. Princeton University Press, New Jersey.

9. Farrely, C. (ed.) (2004) Introduction to Contemporary Political Theory, SAGE Publications, London.

10. Fleurbaey, M.(2002). Equality ofResources Revisited. Ethics, 113(1), 82-105. doi: 10.1086/341320

11. Hart, H. Punishment and Responsibility, 2a edición, Oxford University Press, 2009.

12. Hausman, D. (2009). Equality of Autonomy. Ethics, 119(4), 742-756. doi: 10.1086/605729

13. Kymlicka, W. (2004). Dworkin on freedom and culture. En Dworkin, R. y Burley, J. (Ed.), Dworkin and his Critics. With replies by Dworkin (pp. 111133). Blackwell Publishing, London.

14. (2002) Contemporary Political Philosophy. An Introduction, 2nd, Oxford University Press, New
York.

15. Nozick, R. (1999). Anarchy, State, and Utopia, Blackwell Publishers.

16. 16.Nussbaum, M. (2006). Frontiers of Justice. Disability, Nationality, Species Membership. Harvard University Press, London.

17. Otsuka, M. (2004). Liberty, equality, envy, and abstraction. En Dworkin, R. y Burley, J. (Ed.), Dworkin and his Critics. With replies by Dworkin (pp. 70-78). Blackwell Publishing, London, 2004.

18. Pereira, G. (2004). Medios, Capacidades y Justicia distributiva. La igualdad de recursos de Ronald Dworkin como teoría de medios y capacidades. UNAM, México.

19. Rawls, J. Justice as Fairness. A Restatement, Harvard University Press, London, 2001

20. (1984). Justicia como imparcialidad, Cuadernos de Crítica, No. 32, Instituto de Investigaciones Filosóficas-UNAM, 1984.

21. Roemer, J. (1993). A Pragmatic Theory of Responsibility for the Egalitarian Planner. Philosophy and Public Affairs, 22(2), pp. 146-166.

22. Scheffler, S. (2003). Equality as the Virtue of Sovereigns: A Reply to Ronald Dworkin. Philosophy and Public Affairs, 3(2), 199-206.

23. Sen, A. (1992). Nuevo examen de la desigualdad, Alianza. Madrid: España.

24. Williams, A. (2002). Dworkin on Capability. Ethics, 113(1), 23-39. 10.1086/341323

25. Williams, B. (1993). Recognizing Responsibility, en Williams, B. Shame and Necessity, University of California Press, pp. 50-74. 